\title{
Importance of Geriatric Syndromes in Older Patients with Diabetes with de novo Insulin Treatment: The VEGAS Study
}

\author{
Andrej Zeyfang • Andrea Patzelt-Bath
}

Published online: 24 February 2015

(c) The Author(s) 2015. This article is published with open access at Springerlink.com

\begin{abstract}
Aims The VEGAS study was conducted to evaluate representative data of de novo insulin-treated older patients with type 2 diabetes in the outpatient setting in Germany. Methods In this prospective, multicenter, non-interventional observational study, a nationwide written survey was carried out among practitioners (02/2011-06/2011). Older patients, aged $\geq 70$ years, starting de novo insulin therapy, were documented.

Results Data from 4,858 patients from about 500 centers (mean age: $78.2 \pm 5.4$ years; mean glycosylated hemoglobin $\left.\left[\mathrm{HbA}_{1 \mathrm{c}}\right]: 70 \pm 14.2 \mathrm{mmol} / \mathrm{mol}[8.6 \pm 1.3 \%]\right)$ were collected. The mean target $\mathrm{HbA}_{1 \mathrm{c}}$ value was $55 \pm 6.6 \mathrm{mmol} / \mathrm{mol}(7.2 \pm 0.6 \%) .91 .1 \%$ of geriatric patients were multi-morbid. $96.2 \%$ showed at least one physical or psychological geriatric syndrome. Most of the patients were notably impaired according to their age.
\end{abstract}

A complete list of the study centers can be found in the supplementary data online.

Electronic supplementary material The online version of this article (doi:10.1007/s40801-015-0014-9) contains supplementary material, which is available to authorized users.

\section{A. Zeyfang}

University of Ulm, Institute of Epidemiology,

Albert-Einstein-Allee 41, 89081 Ulm, Germany

\section{A. Zeyfang $(\bowtie)$}

AGAPLESION Bethesda Hospital Stuttgart,

Hohenheimer Strasse 21, 70184 Stuttgart, Germany

e-mail: andrej.zeyfang@bethesda-stuttgart.de

A. Patzelt-Bath

BERLIN-CHEMIE AG, Berlin, Germany
Conventional insulin therapy and basal-supported oral therapy were the most frequently planned treatment regimens (39.1 and $31.1 \%)$. Important factors in the selection of the insulin treatment regimen were an efficient $\mathrm{HbA}_{1 \mathrm{c}}$ decrease $(65.6 \%)$, easy administration $(55.7 \%)$, and also a patient's ability to self-administer insulin (38.5\%). De novo insulin treatment increased care requirements (22.7\%). $22.3 \%$ of the relatives were scheduled to receive special training. Specific training programs for older patients with diabetes were planned in only $7.3 \%$ of cases. Conclusions The data demonstrate the high prevalence of geriatric syndromes during de novo insulin treatment. Individual therapeutic goals and regimes are based on practicability, in particular, the receipt of autonomy and the care requirement. Diabetes education with adapted programs is currently under-represented. Important factors for the choice of an insulin treatment regimen were an efficient $\mathrm{HbA}_{1 \mathrm{c}}$ decrease, easy administration, and a patient's ability for self-administration.

\section{Key Points}

Observational health study of a real-world cohort of older (age $>70$ years), multi-morbid patients with diabetes mellitus starting on insulin treatment.

The first study to establish the reasons, strategies, and expectations of the treating general practitioners in de novo insulin therapy in older patients with diabetes.

A closer examination of the use of educational programs for older patients with diabetes and their carers. 


\section{Introduction}

Diabetes mellitus is a global health problem that will grow in magnitude as a result of worldwide demographic aging [1]. The treatment of older people with diabetes with their agerelated high morbidity and high prevalence of geriatric syndromes (such as immobility, incontinence, dementia) is a great medical and economic challenge in present times [2, 3].

Practice guidelines for the management of diabetes in older people have to consider special conditions such as multi-morbidity, cognitive and physical impairment, and the need to evaluate an individual's goals including life perspective and quality of life [4].

Two leading associations in Germany, the German Diabetes Association (Deutsche Diabetes Gesellschaft, DDG) and the German Geriatric Society, have published evidence-based guidelines for the diagnosis, treatment, and follow-up of diabetes in older patients that combined aspects of diabetology with aspects of clinical geriatric medicine [5]. These guidelines provide recommendations for insulin therapy when the individual therapeutic goal cannot be achieved through diet modification and/or oral anti-diabetic agents (usually for a glycosylated hemoglobin $\left[\mathrm{HbA}_{1 \mathrm{c}}\right]$ value of $>64 \mathrm{mmol} / \mathrm{mol}$ [ $>8 \%$ ]) [5]. Insulin therapy should ideally begin in conjunction with a structured treatment and educational program including for persons of advanced age [5-7]. Furthermore, older people with diabetes sometimes seem to benefit from the anabolic effect of insulin by an improvement in strength, mobility, and, in some cases, cognition [6, 8-10].

Despite a great social interest, data demonstrating the current healthcare situation of de novo insulin-treated older people with diabetes in Germany are scarce. Only a small number of local studies analyzed the healthcare structure in outpatient or inpatient care facilities [11, 12]. Nationwide data are only available for a limited and non-representative number of older persons with type 2 diabetes [13].

This nationwide observational multicenter study was conducted to evaluate representative data of de novo insulin-treated older persons with type 2 diabetes in an outpatient setting in Germany. In this context, both the particular patient population with a focus on geriatric syndromes and the reasons for individual medical decisions were analyzed.

\section{Patients and Methods}

This prospective, multicenter, open-label, non-interventional observational study was conducted from February to June 2011 to gain more insight into important factors and reasons for medical decisions in the first-time insulin treatment of older persons with type 2 diabetes in Germany. A nationwide written survey via a standardized questionnaire was carried out among practitioners specialized in diabetology. There were about 1,150 practitioners specialized in diabetology ("centers") in Germany at that time, according to an official statement of the DDG [14]. They were invited to participate in the study if they received scientific field force visits. A representative number of centers should participate.

Older persons (aged $\geq 70$ years, experiencing multimorbidity and geriatric syndromes) scheduled to receive firsttime insulin therapy were included independently of the insulin preparation used. Geriatric syndromes refers to multifactorial health conditions that occur when the accumulated effects on multiple systems render an older person vulnerable to situational changes [15]. We analyzed the geriatric symptoms: impairment of vision and hearing, fine motor skills, gait, falls, depression, cognition, and urinary and bowel continency. A cognitive deficiency or physical impairment (frailty) was attributed clinically by the general practitioners, multi-morbidity was defined by the presence of three or more different diagnoses. Persons with the following characteristics were excluded from the analysis: age $<70$ years, no documentation of year of birth, or pre-treated with insulin, or persons with incomplete questionnaires.

Patient characteristics, age-related and anamnestic data, glycemic metabolism parameters, and details of the de novo insulin treatment were recorded.

\section{Statistical Analysis}

Data analysis was provided by SAS (Version 9.2). Descriptive statistical methods were used. With respect to quantitative variables, the following statistical parameters were determined: number of valid data, arithmetic mean, standard deviation, range, and selected quantiles. Qualitative data were calculated with absolute and relative frequency distributions. Where calculated frequencies referred to a distinct basic population other than the total patient number of 4,858 (because of different amounts of valid data), the corresponding number is indicated in brackets.

The impact of variables on investigation parameters was evaluated by a subgroup analysis.

\section{Results}

Demographic and Baseline Characteristics

Five hundred and thirty-six centers received 5,398 questionnaires. Five hundred and twenty-four centers returned 5,171 questionnaires and thereof 5,060 questionnaires were completed. One hundred and fifty-one were filled in with 
persons born after 1940, 26 lacked years of birth, and 25 had had insulin before. In total, 4,858 persons from about 500 centers were available for evaluation. The centers were evenly allocated in Germany with regard to areas of high population density (Supplemental Fig. S1). We did not look for differences between rural or urban areas because we did not ask for the residence of the patients. The sex distribution was almost equal (women: $51.2 \%$; men: $48.0 \%$; no data: $0.8 \%$ ). Mean age was $78.2 \pm 5.4$ years, whereby more than one third of the persons $(38.2 \%)$ were at least 80 years old. Of persons with diabetes $(n=4,804)$, $45.5 \%$ were obese with a body mass index $\geq 30 \mathrm{~kg} / \mathrm{m}^{2}$ [16]. Nearly half of the persons had type 2 diabetes for a minimum of 10 years ( $48.6 \%$; mean: $11.0 \pm 7.7$ years; $n=4,689$ ). Further patient characteristics and details of status parameters are given in Table 1 .

The vast majority of the 4,858 patients with diabetes received metformin $(77.7 \%)$ and sulfonylurea $(53.2 \%)$ as previous anti-diabetic therapy. Importantly, in $58.2 \%$ of the metformin-treated patients and in $18.8 \%$ of the sulfonylurea-treated patients, the previous therapy was planned to be continued in combination with insulin (Supplemental Table S1).

Before starting de novo insulin treatment, the mean $\mathrm{HbA}_{1 \mathrm{c}}$ value was $70 \pm 14.2 \mathrm{mmol} / \mathrm{mol}(8.6 \pm 1.3 \%)$. The mean target $\mathrm{HbA}_{1 \mathrm{c}}$ value that was expected by starting on insulin therapy was $55 \pm 6.6 \mathrm{mmol} / \mathrm{mol}(7.2 \pm 0.6 \%)$ (Supplemental Table S2).

\section{Characteristics of the Older Patients}

Of the 4,858 patients, $81.2 \%$ had at least one geriatric syndrome. $32.7 \%$ of the persons were over 80 years of age, $33 \%$ were described as "frail" by their physicians, $32.9 \%$ showed cognitive impairment, and $35.7 \%$ received poly-pharmacotherapy. In total, 4,424 of the 4,858 geriatric persons were multi-morbid (91.1\%). The three most frequently documented chronic diseases were heart disease $(71.5 \%)$, cerebrovascular disease $(33.6 \%)$, and neurological disease $(30.1 \%)$. Furthermore, $29.9 \%$ of patients had osteoarthritis, $11.6 \%$ from malignant diseases and $11.5 \%$ from other diseases, such as chronic obstructive pulmonary disease or arterial hypertension.

Cognitive and physical impairment were documented in nearly all persons (Fig. 1). $96.2 \%$ of the persons with diabetes showed at least one geriatric symptom and more than two thirds $(67.5 \%)$ had at least five of the analyzed geriatric symptoms. Most of the patients were slightly impaired according to their age. However, $27.6 \%$ of all persons were severely handicapped in walking and at least one fall within the last 3 months was reported for almost $45 \%$ of the persons. A cognitive deficit was documented for more than $70 \%$ of the persons. Almost $80 \%$ of the
Table 1 Patient baseline characteristics and status parameters

\begin{tabular}{|c|c|}
\hline \multicolumn{2}{|l|}{ Characteristics/parameters } \\
\hline \multicolumn{2}{|l|}{ Rate [\%] } \\
\hline Women & 51.2 \\
\hline Men & 48.0 \\
\hline No data & 0.8 \\
\hline \multicolumn{2}{|l|}{ Health insurance/health payer ${ }^{\mathrm{a}}[\%]$} \\
\hline Statutory health insurance & 85.1 \\
\hline Private health insurance & 6.3 \\
\hline Health insurance for civil servants & 0.6 \\
\hline Age [years] (range; median) & $\begin{array}{l}78.2 \pm 5.4 \\
\quad(71-102 ; 77)\end{array}$ \\
\hline Body height ${ }^{\mathrm{b}}[\mathrm{cm}]$ & $167.8 \pm 8.9$ \\
\hline Body weight $^{\mathrm{c}}[\mathrm{kg}]$ & $84.7 \pm 16.1$ \\
\hline Abdominal girth ${ }^{\mathrm{d}}[\mathrm{cm}]$ & $104.1 \pm 15.1$ \\
\hline $\mathrm{BMI}^{\mathrm{e}}\left[\mathrm{kg} / \mathrm{m}^{2}\right]$ & $30.1 \pm 5.2$ \\
\hline Blood pressure $^{\mathrm{f}}$ [systolic/diastolic $\left.(\mathrm{mmHg})\right]$ & $\begin{array}{l}140.4 / 82.3 \pm 16.3 / \\
11.3\end{array}$ \\
\hline Creatinine $^{\mathrm{g}}[\mu \mathrm{mol} / \mathrm{L}]$ & $106.10 \pm 35.37$ \\
\hline $\mathrm{HbA}_{1 \mathrm{c}}^{\mathrm{h}}[\mathrm{mmol} / \mathrm{mol}(\%)]$ & $\begin{array}{l}70 \pm 14 \\
\quad(8.6 \pm 1.3)\end{array}$ \\
\hline Fasting blood glucose $\mathrm{e}^{\mathrm{i}}[\mathrm{mmol} / \mathrm{L}]$ & $9.3 \pm 2.64$ \\
\hline Post-prandial blood glucose ${ }^{\mathrm{j}}[\mathrm{mmol} / \mathrm{L}]$ & $12.38 \pm 3.47$ \\
\hline $\begin{array}{l}\text { Duration of diabetes mellitus }{ }^{\mathrm{k}} \text { [years] } \\
\text { (percentiles } 1-99 ; \text { median) }\end{array}$ & $\begin{array}{l}11.0 \pm 7.7 \\
(0.2-34.9 ; 9.8)\end{array}$ \\
\hline
\end{tabular}

Values are indicated as arithmetic mean \pm standard deviation or relative frequencies, when indicated also as (range; median). In total, $n=4,858$ patients have been documented

$B M I$ body mass index, $H B A_{l_{c}}$ glycosylated hemoglobin

${ }^{\text {a }}$ Multiple answers were possible

b $n=4,809$

c $n=4,826$

${ }^{\mathrm{d}} n=3,270$

e $n=4,804$

f $n=4,610 / 4,592$

g $n=4,337$

' $n=4,815$

i $n=4,614$

j $n=4,316$

${ }^{\mathrm{k}} n=4,689$

persons had reduced hearing. Additionally, depressive symptoms were reported for $55.2 \%$ and incontinence for $38.4 \%$ of the study population.

Details of the patients' living conditions, care level, and care requirements before the first-time insulin treatment are given in Supplemental Tables S3, S4, and S5.

Diabetic Complications and Creatinine Clearance

$82.7 \%$ of all persons had diabetic complications, mostly from neuropathy $(55.1 \%)$, macrovascular complications 


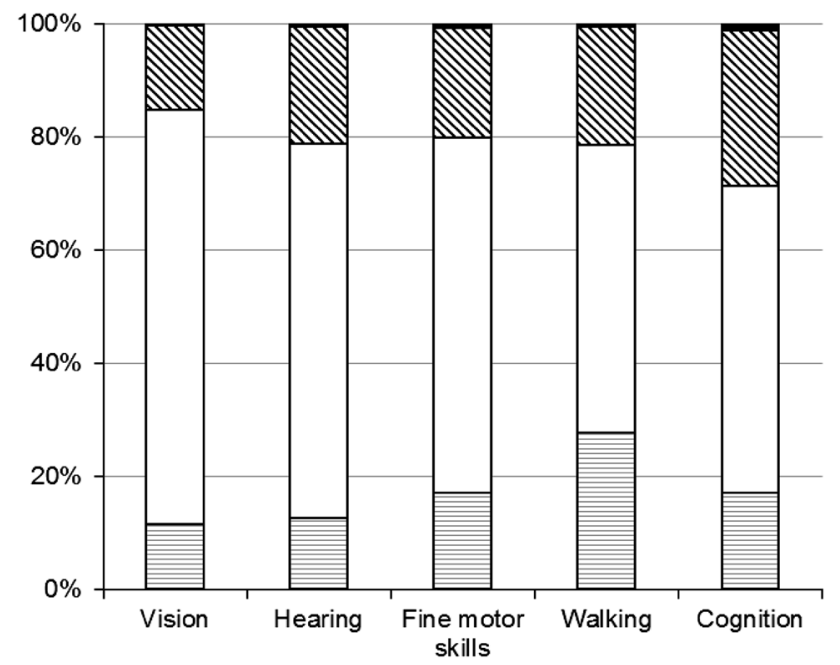

Fig. 1 Cognitive and physical impairment of the geriatric patients $(n=4,858)$. Black bars no data; diagonally striped bars not impaired; white bars slightly impaired appropriate to age; horizontally striped bars severely impaired

(33.8 \%), nephropathy (29.7\%), or retinopathy (28.2\%), but underestimation was likely owing to barriers to access to specialists. $19.8 \%$ of all persons had a diabetic foot syndrome.

Analyzing the creatinine clearance determined by the Modification of Diet in Renal Disease formula revealed that $2,055(42.3 \%)$ of the study population had an estimated glomerular filtration rate $<60 \mathrm{~mL} / \mathrm{min}$ and therefore a moderate or severe loss of renal function. A severe loss of renal function was documented in $233(4.8 \%)$ patients. Patients with nephropathy had more moderate to severe renal insufficiency $(<60 \mathrm{~mL} / \mathrm{min}: 68 \%$ [983], $<30 \mathrm{~mL} /$ min: $11 \%$ [159]; $n=1,445)$ than the overall patient population. In $39.4 \%$ of the 3,777 patients who had received previous metformin therapy there was an estimated glomerular filtration rate of $<60 \mathrm{~mL} / \mathrm{min}$ and for 127 (3.4\%) patients it was $<30 \mathrm{~mL} / \mathrm{min}$. Although metformin is contraindicated in persons with a creatinine clearance $<60 \mathrm{~mL} / \mathrm{min}[5,17]$ in Germany, metformin therapy was planned to be continued during first-time insulin treatment in $40.8 \%$ of the 1,487 persons with moderate to severe loss of renal function.

\section{De novo Insulin Treatment}

The conventional therapy (CT) was the most frequently planned treatment regimen $(39.1 \%)$, followed by the basal-supported oral therapy (BOT) (31.1\%) (Fig. 2). Details on the initial dosages of the different treatment regimens are given in Supplemental Table S6.

A subgroup analysis revealed that older age ( $\geq 80$ years vs. $<80$ years: $45.7 \%[n=1,855]$ vs. $35.1 \%[n=2,997])$,



Fig. 2 Treatment regimen $(n=4,858)$; no data from six subjects $(0.1 \%)$. BOT basal-supported oral therapy, $C T$ conventional therapy, $I C T$ intensive conventional insulin therapy, SIT supplementary insulin therapy

a higher $\mathrm{HbA}_{1 \mathrm{c}} \geq 64 \mathrm{mmol} / \mathrm{mol}$ vs. $<64 \mathrm{mmol} / \mathrm{mol}[\geq 8 \%$ vs. $<8 \%$ ]: $41.6 \%[n=3,261]$ vs. $33.7 \%[n=1,548])$, cognitive impairment (yes vs. no: $42.5 \%[n=3,464]$ vs. $30.5 \%[n=1,337]$ ) or a care level (yes vs. no: $48.6 \%$ $[n=1,600]$ vs. $34.4 \%[n=3,200])$ was more frequent under the CT treatment regimen.

The three most important reasons for choosing the treatment regimen were "efficient decrease of $\mathrm{HbA}_{1 \mathrm{c}}$ " $(65.6 \%)$, "easy administration" (55.7\%), and "targeted treatment of the fasting blood glucose" (44.0\%). Additionally, "targeted treatment of post-prandial blood glucose" (40.2\%), "patient can do it by himself" (38.5\%), "enabled through the nursing care" (18.9\%), "flexibility" (18.5\%), "data situation" (7.7\%), "costs" (3.0\%), and "others" $(4.3 \%)$ were given as further reasons.

More than half of the older patients with diabetes were treated with human insulin alone (51.5\%) (Fig. 3b). Furthermore, $41.4 \%$ of the persons received insulin analogs alone. A subgroup analysis showed that older patients (age $\geq 80$ years vs. age $<80$ years: $54.9 \%[n=1,813]$ vs. $52.1 \%[n=2,895])$, with a longer diabetes duration ( $\geq 10$ years vs. $<10$ years: $53.2 \%[n=2,211]$ vs. $52.8 \%$ $[n=2,335])$ and lower $\mathrm{HbA}_{1 \mathrm{c}}$ values before the treatment change $[<64 \mathrm{mmol} / \mathrm{mol}$ vs. $\geq 64 \mathrm{mmol} / \mathrm{mol}(<8$ vs. $\geq 8 \%$ ): $55.5 \%(n=1,491)$ vs. $52.2 \%(n=3,177)]$ more often received human insulin than the comparative group.

Insulin was administered via a single-use pen in $68.5 \%$ of all persons (Fig. 3a), and in $70.9 \%$ of persons with impaired fine motor skills $(n=3,873)$. The administration was mostly carried out by the patient (Fig. 3c). Injections by others were often associated with cognitive impairment 


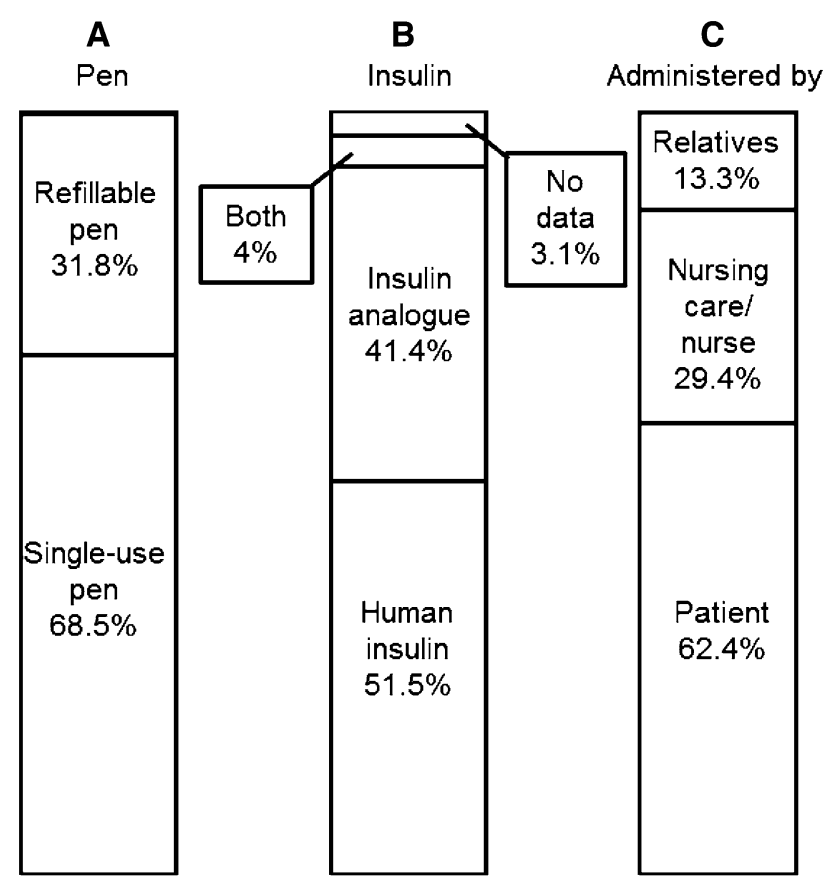

Fig. 3 Insulin and insulin administration $(n=4,858)$. a Administration form. Nine patients used a syringe $(0.2 \%)$, three patients administered via an insulin pump $(0.1 \%)$. b Types of insulin. c Administering patients. Administered by "others": $n=10 ; 0.2 \%$

of the patient. $47.9 \%$ of persons with cognitive impairment $(n=3,464)$ did not self-administer.

The de novo insulin treatment increased care requirements in $22.7 \%$ of all persons with diabetes. $11.2 \%$ required nursing care for the first time (Supplemental Table S5).

Accordingly, increased care requirements after first-time insulin treatment are required more often in patients aged 80 years and older ( $\geq 80$ years vs. $<80$ years: $31.1 \%$ $[n=1,809]$ vs. $18.6 \%[n=2,909])$, with a diabetes duration of at least 10 years ( $\geq 10$ years vs. $<10$ years: $26.1 \%[n=2,221]$ vs. $20.8 \%[n=2,336])$, with $\mathrm{HbA}_{1 \mathrm{C}}$ values of $\geq 64 \mathrm{mmol} / \mathrm{mol} \quad(\geq 8 \%) \quad \geq 64 \mathrm{mmol} / \mathrm{mol}$ vs. $<64 \mathrm{mmol} / \mathrm{mol}(\geq 8$ vs. $<8 \%$ ): $26.8 \%[n=3,175]$ vs. $16.2 \%[n=1,502])$ or in patients with classification into a care level (yes vs. no: $49.7 \%[n=1,574]$ vs. $9.9 \%$ $[n=3,105])$.

\section{Training Programs}

A training program was planned for $3,124(64.3 \%)$ patients and in 1,085 (22.3\%) patients for their relatives. The intended training duration was $5.7 \pm 5.1 \mathrm{~h}$ for older patients and $4.7 \pm 5.1 \mathrm{~h}$ for relatives.

The vast majority of patients with cognitive impairment were also scheduled to attend training programs $(57.2 \%$; $\left.n_{\text {total }} 3,464\right)$. Training programs for relatives and nurses were planned for only 889 and 624 (25.9 and $18.0 \% ; n_{\text {total }}$ $3,464)$ of these persons, respectively.

A training program was specified for only $45.7 \%$ of all patients. In nearly $25 \%$ of all patients, the standard training course for adults with type 2 diabetes (Central Institute of the Association of Statutory Health Insurance Physicians [CI-training course]) was chosen and in approximately $7 \%$ of all patients the MEDIAS 2 program (for middle-aged persons with type 2 diabetes) was chosen. Additionally, a structured diabetes treatment and teaching program (DTTP) specialized for older multi-morbid persons with diabetes, called the SGS (structured geriatric DTTP) [7], was chosen for education for 354 persons $(7.3 \%)$, whereas only for 280 patients $(8.1 \%)$ with cognitive dysfunction $(n=3,464)$ an attendance of SGS was planned. For $436(9.5 \%)$ of all persons other teaching programs were mentioned, such as LINDA, a self-management program for persons with type 1 and type 2 diabetes. Overall, in most of the questionnaires, no teaching program was indicated $(2,639 ; 54.3 \%)$.

\section{Discussion}

The study data impressively demonstrate a high prevalence of geriatric syndromes during de novo insulin treatment of the analyzed patient pool. Persons with diabetes in general have a high prevalence of geriatric syndromes such as functional disabilities, depression, falls, urinary incontinence, pain and dementia, correlated to age, diabetes duration, and control of glycemia and hypertension [18, 19]. Physicians underestimated geriatric diagnostic features in this survey. Although nearly all patients showed at least one physical or cognitive disorder, physicians described their patients in only one third of the cases as "frail" or with "cognitive deficiency". The presence of geriatric syndromes was not clearly associated with special approaches as it should be $[8,20,21]$. The underestimation of geriatric problems including cognitive decline and physical disability is a common dilemma [22, 23].

Besides the geriatric syndromes at the time of first-insulin treatment, health status was also seriously affected. VEGAS participants were affected more severely than the low functioning group with diabetes in AHEAD, a study demonstrating the impact of diabetes on functional status and long-term outcomes, despite corresponding age [3]. Fried et al. [24] noted in the context of aged persons with diabetes that frailty is not synonymous with either comorbidity or disability, but comorbidity is an etiologic risk factor for, and disability is an outcome of frailty. It accounts for the higher direct health costs of diabetes [21].

The most frequent reason for insulin therapy was the necessary decrease in $\mathrm{HbA}_{1 \mathrm{c}}$. Mean $\mathrm{HbA}_{1 \mathrm{c}}$ values previous 
to the initiation of insulin treatment were considerably higher than the target value of $<64 \mathrm{mmol} / \mathrm{mol}(<8 \%)$ recommended by the German Diabetes Association and German Geriatric Society for older people with diabetes [5, 6]. In contrast, individual therapeutic targets reported by the participating physicians were in the lower range of recommended $\mathrm{HbA}_{1 \mathrm{c}}$ for older patients with diabetes [5, 6] and corresponded most closely with the explicit risk-stratified approach of the current Department of Veterans Affairs/Department of Defense guidelines [25]. There is little knowledge about decision-making for targets in Germany. Therapeutic targets should be established between doctors and participants against the background of individual threat according to the disease management program "AOK Curaplan Diabetes Mellitus Type 2" of the German public health insurance [26].

All in all, there was a high multi-morbidity in the sample, most persons with diabetes complications, causing new troubles in diabetes management. In four out of 10 persons with a creatinine clearance of $<60 \mathrm{~mL} / \mathrm{min}$, a continuation of metformin treatment was planned. This poses a problem, as metformin is contraindicated in Germany for use in renal impairment, as it is in hepatic insufficiency, cardiac insufficiency, and all diseases with a risk of elevated lactate levels $[5,17]$. Either the advantages of metformin therapy seemed to be of major importance to the GPs or metformin therapy would be suspended in future.

Important factors of the insulin treatment regimen selection were efficient decrease of $\mathrm{HbA}_{1 \mathrm{c}}$, easy administration, but also the ability of the older patient to selfadminister insulin. The request for easy administration and patient's independence is reflected in the types of the most often planned insulin treatment regimens (CT and BOT) as well as the form of administration (single-use pen).

According to German diabetes guidelines, the therapeutic target of diabetes treatment is the improvement and maintenance of quality of life of older people [5]. Easy administration of insulin has a positive impact on the quality of life of the older patient by a low frequency of daily insulin injections [5]. Human insulin was used more often than insulin analogs, although improved clinical profiles of insulin analogs and premixed analog insulins may be advantageous in older people with diabetes with the ease of use of newer insulin delivery devices [27, 28].

More than $70 \%$ had cognitive deficiency. Knowing that approximately $80 \%$ of the participants had a reduced hearing capacity, the question that arises is whether the cognitive abilities of many persons were possibly underestimated. It was shown that the combination of both disturbances is quite frequent and hearing aids could have positive effects on cognitive function [29, 30].

Participation in a structured treatment program is associated with an improvement in quality of life of older people with type 2 diabetes [31]. Focusing on the needs of older persons can improve diabetes control and reduce acute complications better than standard group education [7]. In this study, participation in a training program was planned for the vast majority, including persons with cognitive deficiency. The SGS program was especially developed for older persons with diabetes, considering the limited resources and learning capabilities of older people. It is done in groups of four to six persons and provides self-management skills especially in insulin therapy. It is effective in improving metabolic control and in maintaining independence in older patients with diabetes [7]. In this study, an adequate education with adapted programs was definitely under-represented for the older patient pool [32]. In addition, the importance of diabetes training for relatives was apparently underestimated. This is of relevance because the diabetes knowledge of related carers can only be rated insignificantly higher than that of the older populations [33].

The strength of the study is the high number of patients reached. with 500 of about 1.150 diabetologic centers evenly allocated in Germany [14]. Even if we do not know the reasons for non-attendance, we believe this is a fairly good result for a survey. A limitation of this study is the lack of operationalization, as most of the geriatric syndromes were only assigned by the experience of the treating practitioner. Further research including a comprehensive geriatric assessment to quantify the resources and deficits of this population should be performed. Furthermore, diabetes complications as nephropathy, retinopathy, and polyneuropathy may be underestimated because of the protocol of this study. The VEGAS study demonstrates that further efforts are required to improve the healthcare situation of older people with diabetes with respect to the high prevalence of geriatric syndromes and co-morbidity during de novo insulin treatment.

Acknowledgments The authors thank the study participants, and investigators for their participation (study centers are listed in the supplement). The authors acknowledge and thank Inga Voß-Karig, medunit, for her assistance in preparing the manuscript for submission.

Funding This study was sponsored by Berlin-Chemie/Menarini (BC), Berlin, Germany.

Conflict of interest $\mathrm{AZ}$ has received lecture honoraria from $\mathrm{BC}$, and he received honoraria for participation as a jury member for the BC-sponsored Silver Star award, including reimbursement for travel expenses in connection with the above-mentioned activities. BerlinChemie gave a Grant for the translation of the structured educational program SGS into the Turkish language. AZ and APB own no shares. No other potential conflicts of interest relevant to this article were reported.

Both authors contributed to the study design, analysis, interpretation, and discussion of the data and writing of the manuscript. APB contributed to data collection. Both authors reviewed, edited, and approved the final manuscript before submission. Results of this study 
were presented in poster format at the 47th Congress of the German Diabetes Association (DDG) 2012, Stuttgart, Germany, and the poster abstract was published in Diabetologie and Stoffwechsel 2012.

Open Access This article is distributed under the terms of the Creative Commons Attribution Noncommercial License which permits any noncommercial use, distribution, and reproduction in any medium, provided the original author(s) and the source are credited.

\section{References}

1. Wild S, Roglic G, Green A, Sicree R, King H. Global prevalence of diabetes: estimates for the year 2000 and projections for 2030. Diabetes Care. 2004;27:1047-53.

2. Sinclair AJ, Conroy SP, Bayer AJ. Impact of diabetes on physical function in older people. Diabetes Care. 2008;31:233-5.

3. Blaum CS, Ofstedal MB, Langa KM, Wray LA. Functional status and health outcomes in older Americans with diabetes mellitus. J Am Geriatr Soc. 2003;51:745-53.

4. Sinclair A, Morley JE, Rodriguez-Mañas L, Paolisso G, Bayer T, Zeyfang A, et al. Diabetes mellitus in older people: position statement on behalf of the International Association of Gerontology and Geriatrics (IAGG), the European Diabetes Working Party for Older People (EDWPOP), and the International Task Force of Experts in Diabetes. J Am Med Dir Assoc. 2012;13:497-502.

5. Hader C, Beischer W, Braun A, Dreyer M, Friedl A, Füsgen I, et al. Evidence-based guideline by the German Diabetes Association and the German Geriatric Society: diagnosis, treatment and follow-up of diabetes mellitus in the elderly [article online], 2006. Available from http://www.deutsche-diabetesgesellschaft.de/leitlinien/englische-versionen.html. Accessed 22 Oct 2012.

6. Zeyfang A, Bahrmann A, Wernecke J. Diabetes mellitus im Alter. Diabetologie. 2011;6:S170-5.

7. Braun AK, Kubiak T, Kuntsche J, Meier-Höfig M, Müller UA, Feucht I, et al. SGS: a structured treatment and teaching programme for older patients with diabetes mellitus: a prospective randomised controlled multi-centre trial. Age Ageing. 2009;38: 390-6.

8. Rdzak GM, Abdelghany O (2014): Does insulin therapy for type 1 diabetes mellitus protect against Alzheimer's disease? Pharmacotherapy. 2014. doi:10.1002/phar.1494.

9. Mallery LH, Ransom T, Steeves B, Cook B, Dunbar P, Moorhouse P. Evidence-informed guidelines for treating frail older adults with type 2 diabetes: from the Diabetes Care Program of Nova Scotia (DCPNS) and the Palliative and Therapeutic Harmonization (PATH) program. J Am Med Dir Assoc. 2013;14(11): S801-8.

10. Kravitz E, Schmeidler J, Schnaider BM. Type 2 diabetes and cognitive compromise: potential roles of diabetes-related therapies. Endocrinol Metab Clin North Am. 2013;42(3):S489-501.

11. Coll-Planas L, Bergmann A, Schwarz P, Guillén-Grima F, Schulze J. Quality of care among older adults with diabetes mellitus: comparison between community-dwelling adults attended to by home care services and nursing home residents in Dresden. Z Arztl Fortbild Qualitatssich. 2007;101:623-9.

12. Bahrmann A, Abel A, Specht-Leible N, Abel A, Wörz E, Hölscher $\mathrm{E}$, et al. Treatment quality in geriatric patients with diabetes mellitus in various home environments. Z Gerontol Geriatr. 2010;43:386-92.
13. Zeyfang A, Dippel FW, Bahrmann A, Feucht I, Hamann O, Hodeck K. Health services research in insulin-treated geriatric patients in Germany in nursing homes or ambulatory care: results of the LIVE-GERI-study. Diabetologie. 2010;5:293-300.

14. Siegel EG, Siegel E. Diabetes DE. Deutscher Gesundheitsbericht Diabetes 2012. Mainz: Kirchheim + Co GmbH; 2012. ISSN 1614-824X.

15. Inouye SK, Studenski S, Tinetti ME, Kuchel GA. Geriatric syndromes: clinical, research, and policy implications of a core geriatric concept. J Am Geriatr Soc. 2007;55:780-91.

16. WHO. Obesity: preventing and managing the global epidemic. Report of a WHO consultation. World Health Organ Tech Rep Ser. 2000;894:1-253.

17. BfArM. Bulletin zur Arzneimittelsicherheit. Informationen aus BfArM und PEI. 2011;(3):6-9.

18. Araki A, Ito H. Diabetes mellitus and geriatric syndromes. Geriatr Gerontol Int. 2009;9(2):S105-14.

19. Cigolle CT, Lee PG, Langa KM, Lee YY, Tian Z, Blaum CS. Geriatric conditions develop in middle-aged adults with diabetes. J Gen Intern Med. 2011;26(3):272-9.

20. Durso SC. Using clinical guidelines designed for older adults with diabetes mellitus and complex health status. JAMA. 2006;295:1935-40.

21. Rockwood K, Awalt E, Carver D, MacKnight C. Feasibility and measurement properties of the functional reach and the timed up and go tests in the Canadian study of health and aging. J Gerontol A Biol Sci Med Sci. 2000;55:M70-3.

22. Gregg EW, Engelgau MM, Narayan V. Complications of diabetes in elderly people. BMJ. 2002;325:916-7.

23. Volpato S, Maraldi C, Fellin R. Type 2 diabetes and risk for functional decline and disability in older persons. Curr Diabetes Rev. 2010;6:134-43.

24. Fried LP, Tangen CM, Walston J, Newman AB, Hirsch C, Gottdiener J, et al. Frailty in older adults: evidence for a phenotype. J Gerontol A Biol Sci Med Sci. 2001;56:M146-56.

25. Kirsh SR, Aron DC. Choosing targets for glycaemia, blood pressure and low-density lipoprotein cholesterol in elderly individuals with diabetes mellitus. Drugs Aging. 2011;28:945-60.

26. AOK Bayern. AOK Curaplan-Great care right from the start! Customer information for diabetes mellitus Type 2. Available from http://www.aok.de/bayern/gesundheit/behandlung-programmefuer-chronisch-kranke-aok-curaplan-englisch-245265.php. Accessed 16 Dec 2014.

27. Franchin A, Corradin ML, Giantin V, Rossi F, Zanatta F, Attanasio F, et al. Diabetes in a geriatric ward: efficacy and safety of new insulin analogs in very old inpatients. Aging Clin Exp Res. 2012;24(3 Suppl):17-9.

28. Tanwani LK. Insulin therapy in the elderly patient with diabetes. Am J Geriatr Pharmacother. 2011;9:24-36.

29. Lin FR. Hearing loss in older adults: who's listening? JAMA. 2012;307:1147-8.

30. Pacala JT, Yueh B. Hearing deficits in the older patient: "I didn't notice anything". JAMA. 2012;307:1185-94.

31. Trento M, Passera P, Borgo E, Tomalino M, Bajardi M, Cavallo F, et al. A 5-year randomized controlled study of learning, problem solving ability, and quality of life modifications in people with type 2 diabetes managed by group care. Diabetes Care. 2004;27:670-5.

32. Bourdel-Marchasson I, Dugaret E, Regueme S. Disability in older people with diabetes: issues for the clinician. Br J Diabetes Vasc Dis. 2012;12:135-40.

33. Sinclair AJ, Armes DG, Randhawa G, Bayer AJ. Caring for older adults with diabetes mellitus: characteristics of carers and their prime roles and responsibilities. Diabetes Med. 2010;27:1055-9. 